\title{
The biology of malignant breast tumors has an impact on the presentation in ultrasound: an analysis of 315 cases
}

S Wojcinski ${ }^{1 *}$, N Stefanidou ${ }^{2}$, P Hillemanns $^{1}$ and F Degenhardt ${ }^{3}$

\begin{abstract}
Background: The aim of this study was to evaluate the relation of some ultrasound morphological parameters to biological characteristics in breast carcinoma.

Methods: Ultrasound data from 315 breast masses were collected. We analyzed the ultrasound features of the tumors according to the ACR BI-RADS -US classification system stratified by hormone receptor status, HER2 status, histology grade, tumor type (ductal versus lobular), triple-negativity, breast density, tumor size, lymph node involvement and patient's age.

Results: We found a variety of ultrasound features that varied between the groups. Invasive lobular tumors were more likely to have an angulated margin (39\% versus $22 \%, \mathrm{p}=0.040$ ) and less likely to show posterior acoustic enhancement ( $3 \%$ versus $16 \%, p=0.023$ ) compared to invasive ductal carcinoma. G3 tumors were linked to a higher chance of posterior acoustic enhancement and less shadowing and the margin of $\mathrm{G} 3$ tumors was more often described as lobulated or microlobulated compared to G1/G2 tumors (67\% versus $46 \%, p=0.001$ ). Tumors with an over-expression of HER2 exhibited a higher rate of architectural distortions in the surrounding tissue, but there were no differences regarding the other features. Hormone receptor negative tumors were more likely to exhibit a lobulated or microlobulated margin ( $67 \%$ versus $50 \%, p=0.037$ ) and less likely to have an echogenic halo (39\% versus $64 \%, p=0.001)$. Furthermore, the posterior acoustic feature was more often described as enhancement (33\% versus 13\%, $p=0.001$ ) and less often as shadowing (20\% versus $47 \%, p<0.001)$ compared to hormone receptor positive tumors.

Conclusion: Depending on their biological and clinical profile, breast cancers are more or less likely to exhibit the typical criteria for malignancy in ultrasound. Moreover, certain types of breast cancer tend to possess criteria that are usually associated with benign masses. False-negative diagnosis may result in serious consequences for the patient. For the sonographer it is essential to be well aware of potential variations in the ultrasound morphology of breast tumors, as described in this paper.
\end{abstract}

Keywords: Breast ultrasound, Cancer detection, Ultrasound features, Tumor biology

\section{Background}

Breast cancer is not a single disease. A great diversity concerning histopathology, immunohistochemistry, genetics and clinical presentation must be considered. The knowledge about fundamental tumor characteristics is gradually evolving and the elementary pathological division of

\footnotetext{
*Correspondence: s@wojcinski.de

'Department for Obstetrics and Gynecology, Hannover Medical School, Hannover, Germany

Full list of author information is available at the end of the article
}

breast tumors into ductal, lobular and other types becomes more and more complex.

The Nottingham modification of the Bloom-Richardson grading system, also known as Nottingham Histology Grade (NHG), provides a mean for the description of tumor biology [1,2]. Low-grade tumors (i.e. G1) imply a better prognosis than high-grade tumors (i.e. G3) [3]. In 1960, Elwood Jensen first described the estrogen receptor (ER) and provided the basis for a more profound understanding of breast cancer [4]. Over-expression of the human epidermal growth factor receptor 2 (HER2) in breast

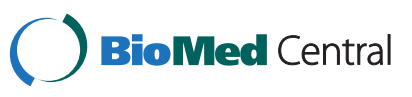


cancer was recognized in the 1980s and provided both a prognostic factor and a predictive factor [5]. HER2overexpressed tumors are known to progress rapidly and have a short interval to distant metastases [6]. On the other hand, the HER2-receptor is the target for an effective therapy, the antibody-based drug Trastuzumab [7].

Nowadays, a much deeper insight into the molecular backgrounds of breast cancer exists. Just recently, gene expression profiles demonstrated that there are at least five different intrinsic subtypes of breast cancer (luminal A, luminal B, claudin-low, HER2-enriched, and basallike) [8-10]. The progression of a tumor, the time and the pattern of distant metastasis and finally the prognosis of the disease are all highly driven by factors that are intrinsic to the distinct tumor type. The tumor biology may also have an influence on the presentation of malignant lesions in breast imaging.

Breast ultrasound, alone or as an adjunct to mammography, is a precise imaging modality with high sensitivity and specificity in the evaluation of breast lesions [11-13]. The standardized American College of Radiology BI-RADS ${ }^{\oplus}$-US-classification for breast tumors provides a variety of categories with predefined terminology to describe the sonographic appearance of a breast lesion [14].

The accurate prediction of the malignant or benign character of a lesion plays a crucial role for the patient, but false-negative and false-positive results may occur. Breast cancer may simulate a benign lesion and vice versa, as there is some overlap in the sonographic features of malignant and benign tumors. Triple-negative breast cancer (TNBC), for example, exhibits significantly different features in ultrasound than non-TNBC [15]. False-positive diagnosis may result in an elevated rate of unnecessary biopsies. The false-negative diagnosis of breast cancers may result in delayed diagnosis and a worse outcome for the patient. Therefore, knowledge about the classic presentation of breast cancer in ultrasound and possible variations in distinct subtypes of breast cancer is crucial for the examiner to determine the malignant or benign character of a lesion precisely.

We scrutinized whether the sonomorphology of malignant breast tumors is correlated to biological features of the tumor.

\section{Methods}

\section{General design and image database}

Our study was carried out at the Breast Cancer Center of Franziskus Hospital in Bielefeld, Germany. Patients with a sonographically visible lesion that proved to be malignant were regarded as being suitable for our study. Patients with recurrent breast cancer, inflammatory breast cancer and tumors involving the skin were excluded.
From the hospital database, 435 consecutive breast cancer patients who attended our institution between October 2008 and January 2011 were retrospectively collected. Digitally recorded ultrasound images were available for 383 of the 435 breast cancer patients. Of these patients, 62 were excluded as they presented noninvasive breast cancer (ductal carcinoma in situ, DCIS) and 6 were excluded as data concerning medical history, receptor status, tumor stage, and/or treatment were missing. Following their exclusion, we created a database containing clinical data and digital ultrasound images from 315 patients.

As the ultrasound images had been obtained using a standard of care clinical protocol within the routine practice of our breast cancer center, our institutional ethics committee did not require additional approval for this non-interventional retrospective study design. The underlying ultrasound examinations were performed by one of four senior consultants in breast diagnostics, all of whom had at least 5-years' experience in breast ultrasound. The examiners applied two high-end ultrasound scanners: The Siemens ACUSON S2000 ${ }^{\mathrm{rm}}$ ultrasound system (Siemens Medical Solutions, Inc, Mountain View, CA, USA) equipped with the 18 L6 HD linear transducer $(5.5-18 \mathrm{MHz}, 5.6 \mathrm{~cm})$ and the Hitachi HI VISION 900 ultrasound system (Hitachi Medical Corporation, Inc, Tokyo, Japan) equipped with the EUP L54M linear transducer $(6-13 \mathrm{MHz}, 5.0 \mathrm{~cm})$. As standard of care, all patients received bilateral whole breast ultrasound and sonographic evaluation of the axillary regions. According to the diagnostic standards, the B-mode pictures of the tumor were documented in two planes (sagittal and horizontal).

\section{Image analysis}

The anonymized image database was analyzed by the author SW, a DEGUM (German Society for Ultrasound in Medicine) level II certified senior consultant in gynecology with 7 years' experience in breast ultrasound [16]. SW was blinded to the patients' characteristics and histological results and evaluated the 315 lesions according to the ACR BI-RADS ${ }^{-}$-US classification system and the recommendations of the DEGUM $[14,17]$ :

- Shape: Oval, round or irregular;

- Orientation: Horizontal (i.e. parallel), indifferent (including round), vertical or not determinable;

- Margin: Circumscribed or not circumscribed (with any of the following)

- Indistinct margin: Yes or no;

- Lobulated margin: Yes or no;

- Microlobulated margin: Yes or no;

- Angulated: Yes or no;

- Spiculated: Yes or no; 
- Lesion boundary: Echogenic halo or abrupt interface;

- Echo pattern: Anechoic, hypoechoic, isoechoic, hyperechoic or complex;

- Posterior acoustic features: Shadowing, no posterior acoustic features, enhancement or combined pattern;

- Architectural distortion of the surrounding tissue: Yes or no;

- Changes in Cooper's ligaments: Disrupted or displaced.

Then, the results from the systematic image interpretation were merged with the clinical data of the patients. Comparisons of baseline demographic data, tumor characteristics, and ultrasound features were made between the following groups:

- Breast density: ACR 1 and 2 versus ACR 3 and 4;

- Tumor type: invasive ductal carcinoma (IDC) versus invasive lobular carcinoma (ILC);

- Tumor grade: $\mathrm{G} 1$ and $\mathrm{G} 2$ versus G3 ; G1 versus G2 and G3;

- HER2 status: negative versus positive;

- Hormone receptor (HR) status: negative versus positive;

- Lymph node involvement: N0 versus N+;

- Tumor size: T1 versus T2, T3 and T4;

- Age: $<40$ years versus $>40$ years; $<50$ years versus $>50$ years; $<60$ years versus $>60$ years.

- Triple-negativity: TNBC versus non-TNBC.

Concerning the tumor type, most of the cases revealed to be IDC or ILC (84.7\%). Therefore, other rare types (e.g. mucinous, medullary, tubular, mixed forms) were excluded from this distinct analysis. Vascularity and elasticity were not analyzed, as there were not enough images in our database that displayed these features.

\section{Pathology and immunohistochemistry}

All pathological and immunohistochemical examinations concerning the workup of the tumor tissue were routinely performed by the pathology lab of our breast cancer center. The laboratory regularly participates in the recommended round robin tests for quality assurance. ER, PR, and HER2 were determined by immunohistochemistry. For ER and PR, the cutoff level for receptor positivity was defined as $\geq 1 \%$. HER 2 positivity was defined as strong complete membrane staining of $\geq 10 \%$ of the tumor cells (i.e. Score 3+). An additional fluorescent in situ hybridization (FISH) assay was performed to detect possible gene amplification and HER2 positivity for Score 2+. Score 1+ and Score 0 were defined as HER2negative.

\section{Statistical analysis}

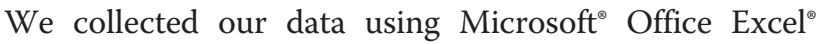
2007 (Microsoft Corporation). The author NS performed the statistical analysis and the results were validated by the author SW. The analysis was performed using MedCalc ${ }^{\circ} 11.6$ statistical software (MedCalc Software bvba, Belgium). The Student's t-test was used for numerical data and comparison of means. Ultrasonographic features of TNBC and non-TNBC were compared using Fisher's exact test for univariate distributions and Yates' chi-square test for multivariate distributions of categorical data. When Yates' chi-square test was found to be significant, pairwise comparisons were performed using Fisher's exact test. Statistical significance was assumed at $\mathrm{p}<0.05$ for all tests.

\section{Results}

Clinical examples for different tumor types are given in Figures 1, 2, 3, 4 and 5. The results concerning the sonographic presentation of the tumors are summarized in Figure 6. The clinical aspects of the tumors are summarized Figure 7. Key aspects are described in the following paragraphs and will be discussed in the next section.

\section{Breast density}

The pre-existing breast density had little effect on the sonomorphology of the tumors. Nevertheless, in dense breast tissue (according to the American College of Radiology, ACR 3 and 4) tumors were more likely to have a horizontal orientation than in less dense breast tissue $(53 \%$ versus $39 \%, \mathrm{p}=0.04)$.

\section{Tumor type}

IDC and ILC cancer showed two different ultrasound features. ILC was more likely to have an angulated margin ( $39 \%$ versus $22 \%, p=0.040$ ) and less likely to show posterior acoustic enhancement ( $3 \%$ versus $16 \%, \mathrm{p}=0.023$ ).

\section{Tumor grade}

Compared to moderately and well differentiated tumors, poorly differentiated tumors (i.e. G3) were linked to a higher chance of posterior acoustic enhancement and less shadowing (31\% versus 9\%, $\mathrm{p}<0.001 ; 25 \%$ versus $49 \%, \mathrm{p}<0.001$ ). Furthermore, the margin of G3 tumors was more often described as lobulated or microlobulated compared to G1/G2 tumors (67\% versus $46 \%, \mathrm{p}=0.001$ ).

\section{HER2 status}

We found only one ultrasound feature that was associated with HER2-positivity. Tumors with an over-expression of HER2 exhibited a higher rate of architectural distortions in the surrounding tissue. 


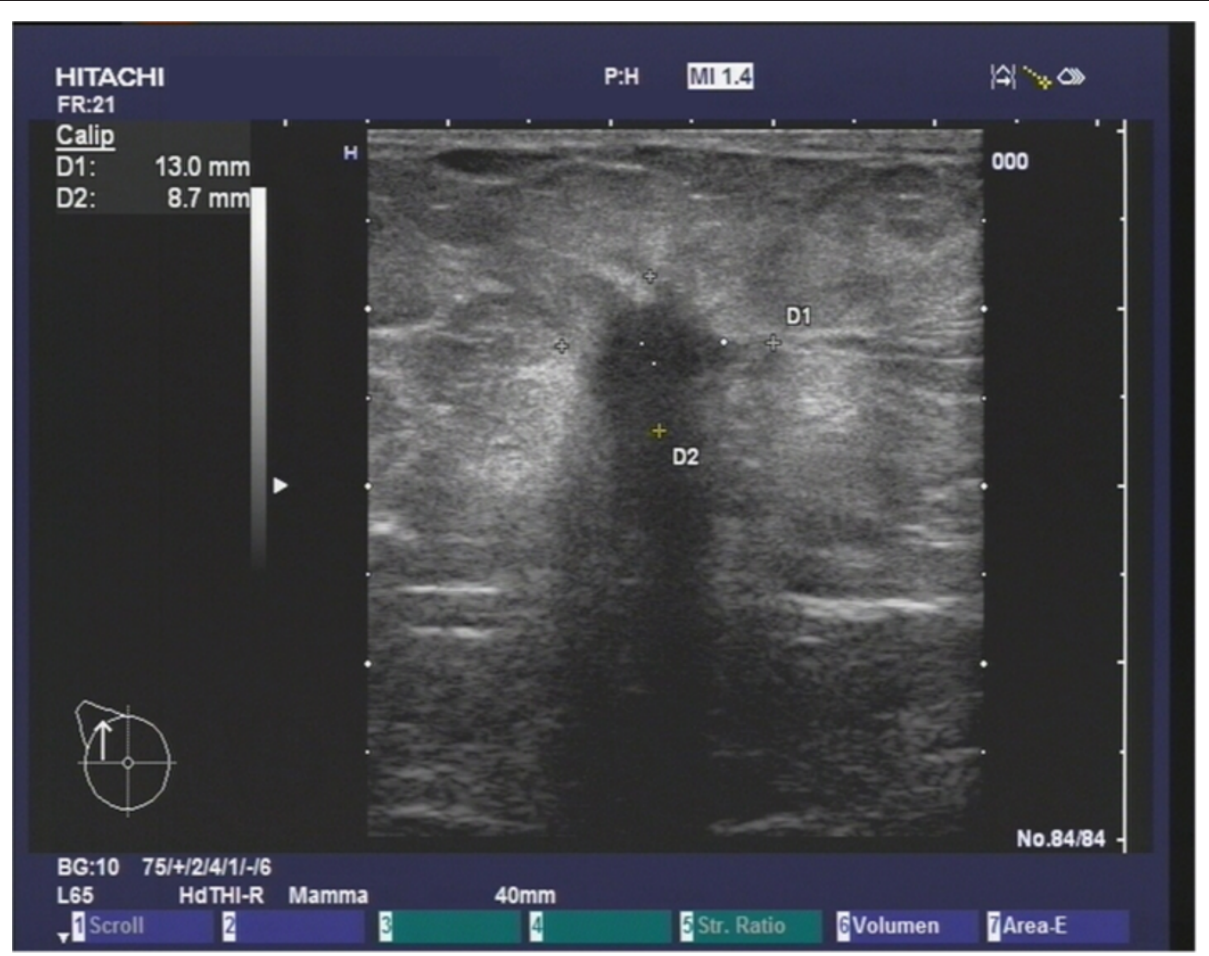

Figure 1 Invasive ductal carcinoma in a $\mathbf{7 2}$ year old patient (HR positive, Her2 negative, G2). The tumor exhibits typical ultrasound criteria for malignancy (irregular, hypoechoic mass with an indistinct, spiculated margin, an echogenic halo, posterior shadowing and architectural distortion of the surrounding tissue).

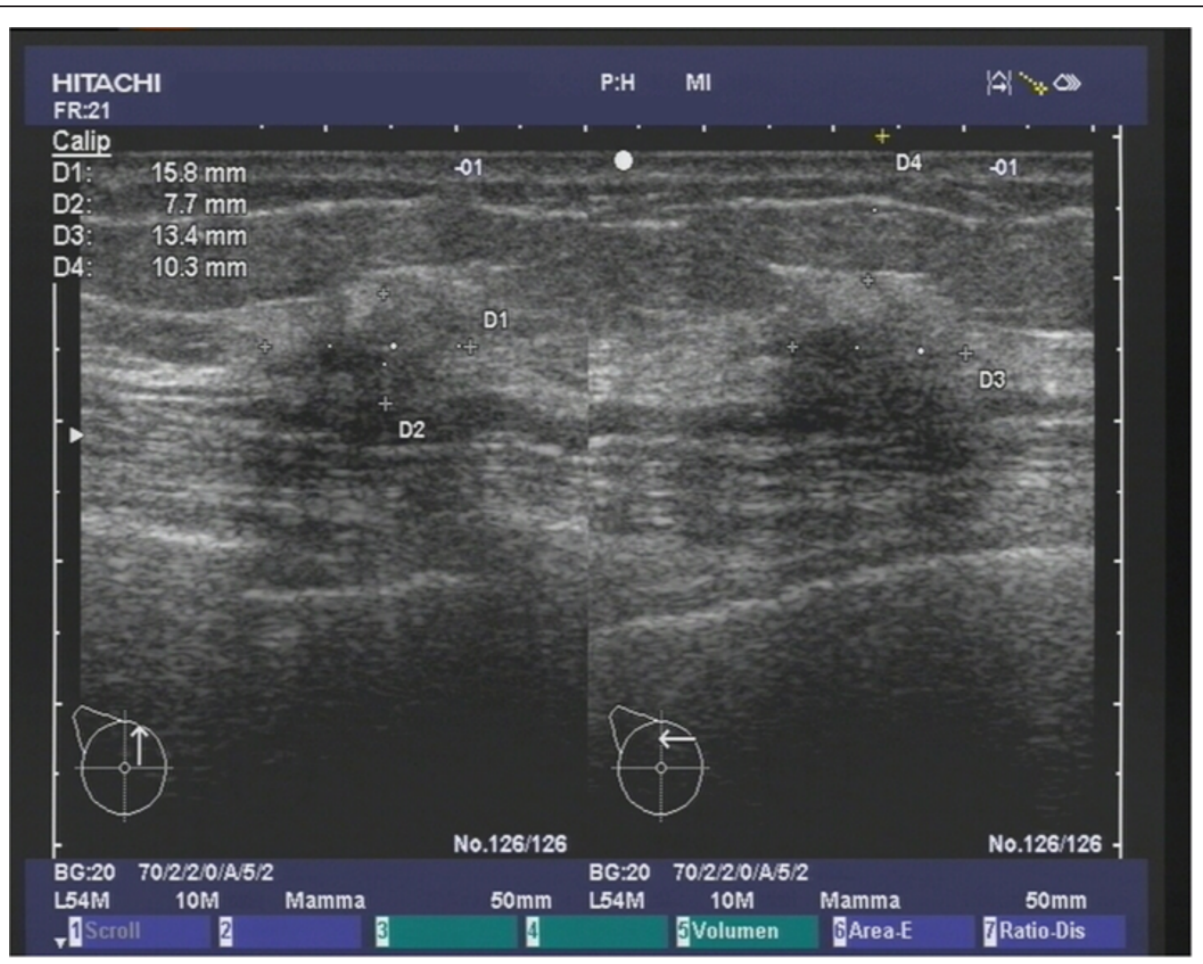

Figure 2 Invasive lobular carcinoma in a 75 year old patient (HR positive, Her2 negative, G2). The tumor appears as a hypoechoic architectural distortion with an indistinct, angulated margin. 


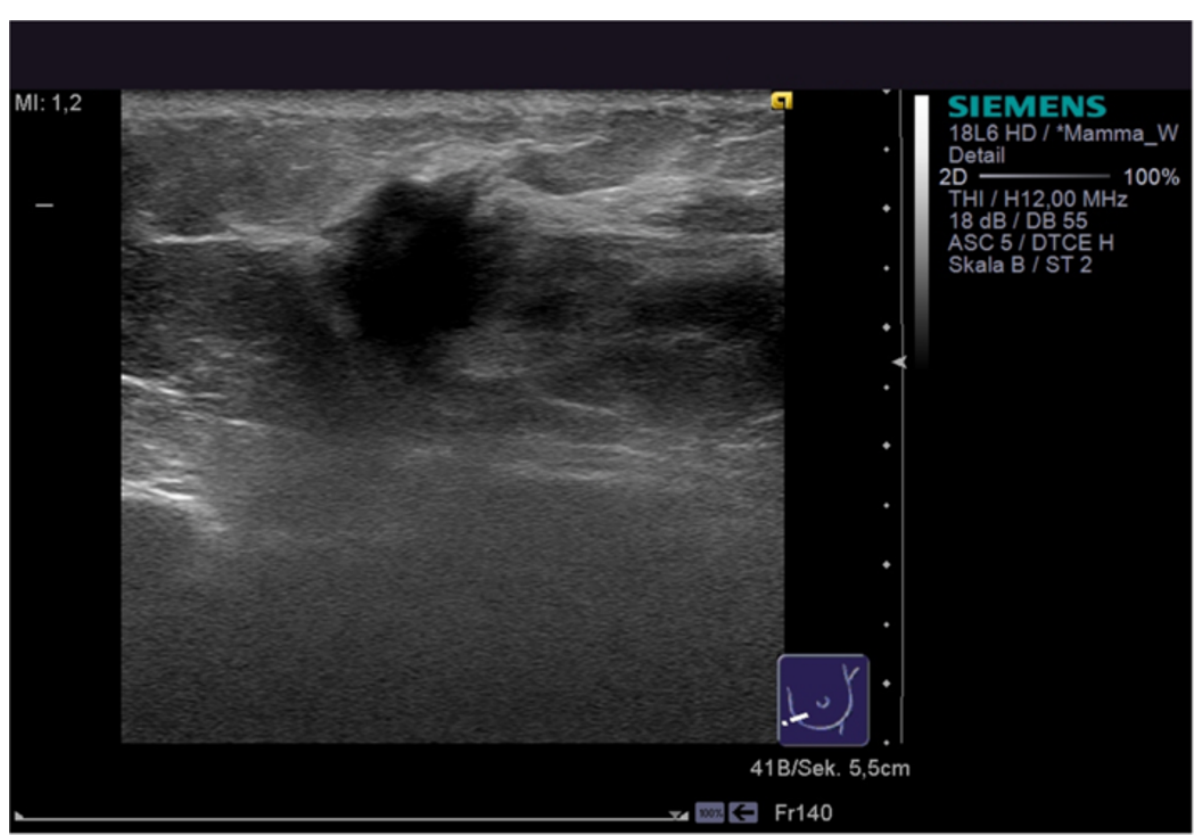

Figure $\mathbf{3}$ Her2/neu-positive HR-positive tumor in a $\mathbf{5 7}$ year old patient (G3, invasive ductal). The tumor presents as a hypoechoic mass with relevant architectural distortion of the surrounding tissue.

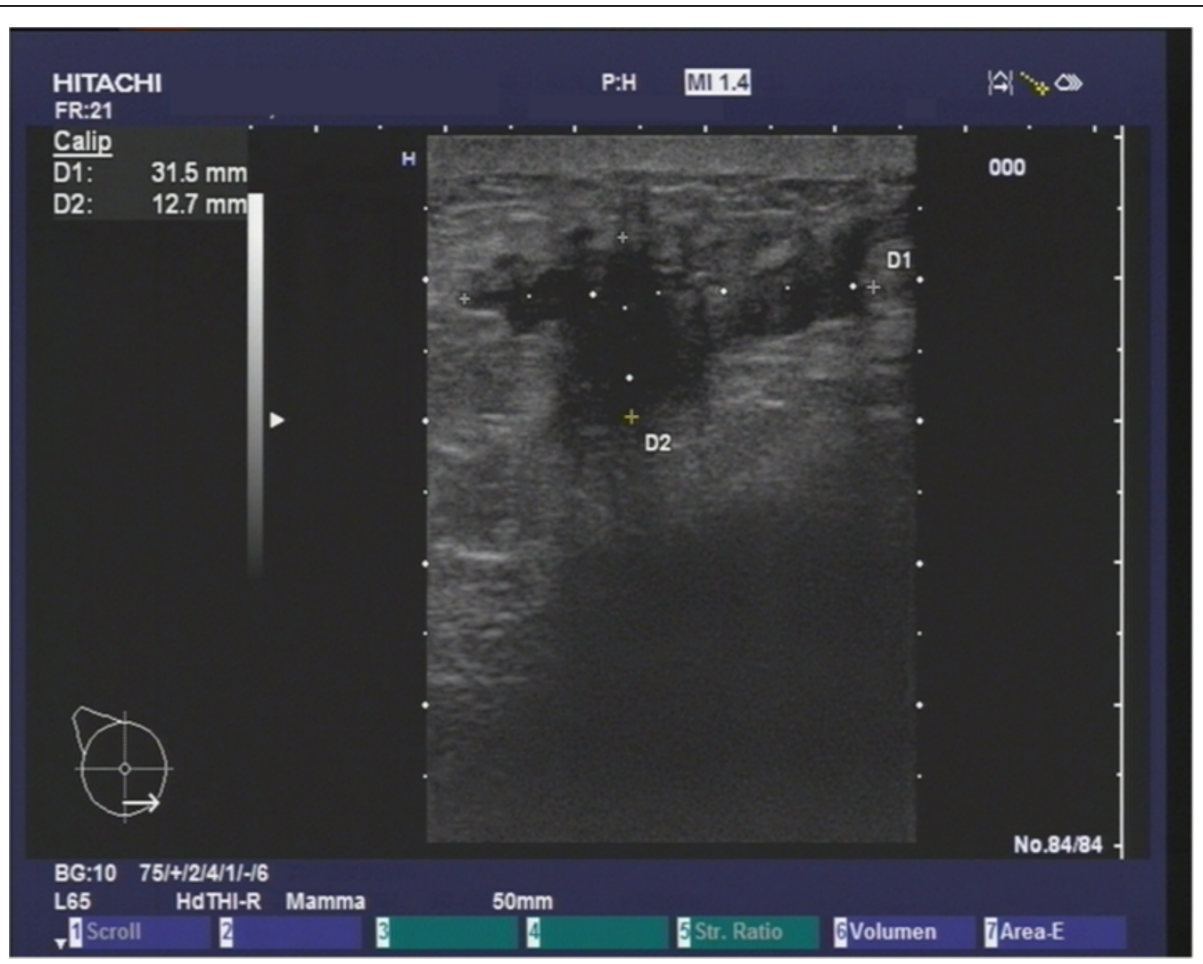

Figure 4 Her2/neu-positive HR-negative tumor in a $\mathbf{4 7}$ year old patient (G3, invasive ductal). The tumor presents as a bizarre, hypoechoic mass with architectural distortion of the surrounding tissue and a widely lobulated or microlobulated margin, but no echoic halo. 


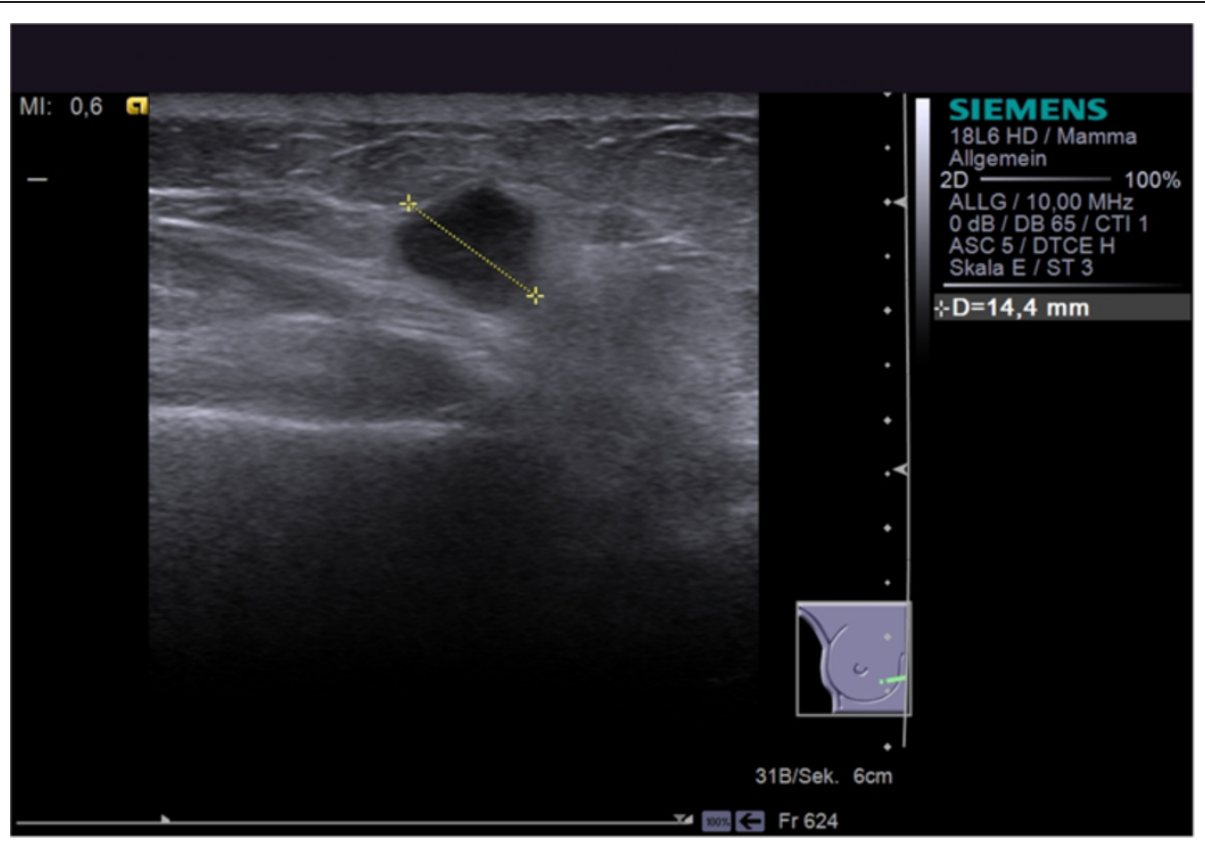

Figure 5 Triple-negative breast cancer in a $\mathbf{5 2}$ year old patient (G3, invasive ductal). The tumor appears as a lobulated, hypoechoic mass. The ligaments are displaced rather than disrupted.

\section{Hormone receptor status}

The HR status had a relevant impact on the sonomorphology. Tumors that neither expressed estrogen nor progesterone receptors were more likely to exhibit a lobulated or microlobulated margin (67\% versus $50 \%$, $\mathrm{p}=0.037)$ and less likely to have an echogenic halo $(39 \%$ versus $64 \%, \mathrm{p}=0.001)$. Furthermore, the posterior acoustic feature was more often described as enhancement (33\% versus $13 \%, \mathrm{p}=0.001)$ and less often as shadowing $(20 \%$ versus $47 \%, \mathrm{p}<0.001)$ compared to $\mathrm{HR}$ positive tumors. Finally, displacement of the Cooper's ligaments (instead of disruption) was more often found in ER/PR negative tumors (39\% versus $14 \%, \mathrm{p}=0.002)$.

\section{Tumor size}

Several ultrasound features were dependent on the tumor size. Small tumors (i.e. T1) were more likely to have a round or oval shape $(33 \%$ versus $21 \%, \mathrm{p}=0.026)$ and less likely to exhibit a lobulated or angulated/spiculated margin $(15 \%$ versus $29 \%, \mathrm{p}=0.002 ; 29 \%$ versus $41 \%, \mathrm{p}=0.040)$. Furthermore, small tumors showed less architectural distortions (71\% versus $90 \%, \mathrm{p}<0.001)$.

\section{Age}

Patients' age had a relevant influence on the sonomorphology of the tumors. Depending on the cut-off for the age groups, we obtained the following results: In younger patients, the tumors were more likely to present with a round or oval shape and exhibit a lobulated or microlobulated margin. On the other hand, an angulated margin was less often observed. In the group of older patients, an echogenic halo was described more frequently. In young patients, a posterior acoustic enhancement was more often seen and shadowing was less often. Furthermore, architectural distortions were less frequently described in young patients and the Cooper's ligaments were more often described as displaced rather than disrupted.

\section{Triple-negative breast cancer}

As described elsewhere, triple negativity of breast cancer has a relevant effect on the sonomorphology. The margin of TNBC was more frequently described as lobulated and/or microlobulated (76\% versus $50 \%, \mathrm{p}=0.005)$ and the echogenic halo was observed significantly less often compared to non-TNBC (39\% versus 63\%, $\mathrm{p}=0.014)$. Cooper's ligaments were displaced rather than disrupted in TNBC in comparison to non-TNBC (42\% versus $14 \%$, $\mathrm{p}=0.003)$. Posterior acoustic enhancement was more frequent in TNBC (36\% versus $13 \%, \mathrm{p}=0.001$ ) and posterior acoustic shadowing less often observed (27\% versus $47 \%, \mathrm{p}=0.040)$.

Tumor characteristics with impact on the sonomorphology Overall, we performed 12 group comparisons with respect to the ultrasound features. The groups were defined either by clinical characteristics (e.g. age, breast density) or by the tumor biology (e.g. histology grade, receptor status, HER2 status). Depending on the groups observed, the number of significantly different ultrasound 


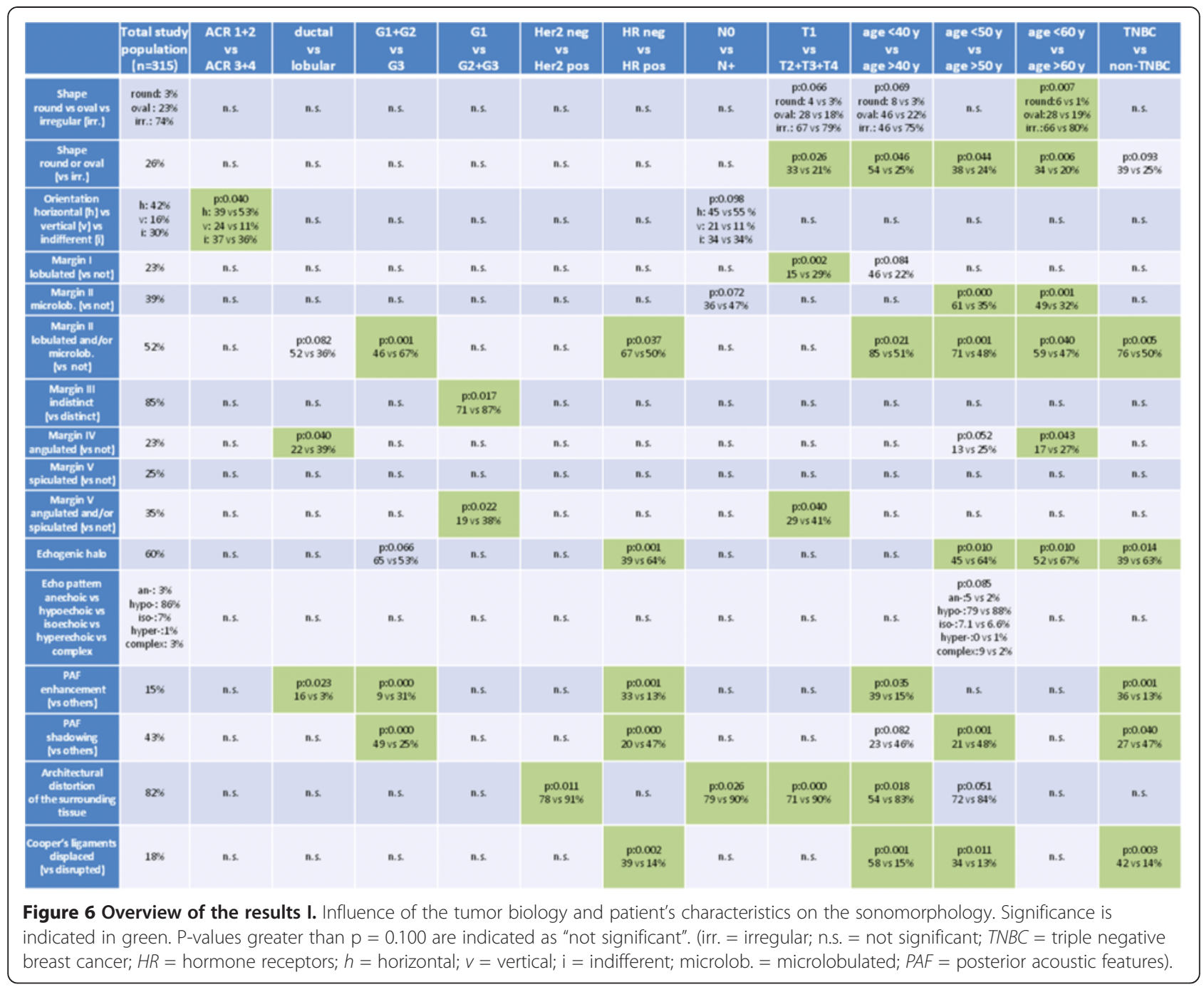

features varied from one different feature between groups to five different features, respectively. We found numerous differences comparing HR positive and hormone receptor negative tumors (i.e. rate of lobulated or microlobulated margin, presence of echogenic halo, posterior acoustic features and changes in Cooper's ligaments) and comparing TNBC and non-TNBC. Furthermore, patient's age (independent from the chosen cut-off) had a considerable effect on the sonomorphology of tumors. Regarding the tumor size, T1 tumors frequently exhibited different features than larger tumors (i.e. shape, presence of lobulated margin, rate of angulated or spiculated margin and architectural distortions) [Figure 6].

\section{Sonographic features that frequently varied between the groups}

We compared 16 ultrasound characteristics between the groups in different categories. Focusing on the ultrasound features, the tumor biology proved a considerable effect on various elements. Amongst others, the presence of a lobulated or microlobulated margin and the presence of an echogenic halo were relevantly influenced by the tumor biology. Furthermore, the posterior acoustic features frequently varied between the investigated groups. Finally, the frequency of architectural distortions and changes of the Cooper's ligaments were frequently dissimilar between the groups [Figure 6].

\section{Discussion}

Is it plausible, that the tumor biology has an impact on the sonomorphology?

Breast cancer is not merely characterized by features that can obviously be detected by clinical examination, medical imaging or visual evaluation of a tumor specimen, but rather by distinct intrinsic attributes. Essential tumor characteristics, like histology grade, hormone receptor status and HER2 expression, have a biological, proteomic or genetic background. Therefore, the characterization of 


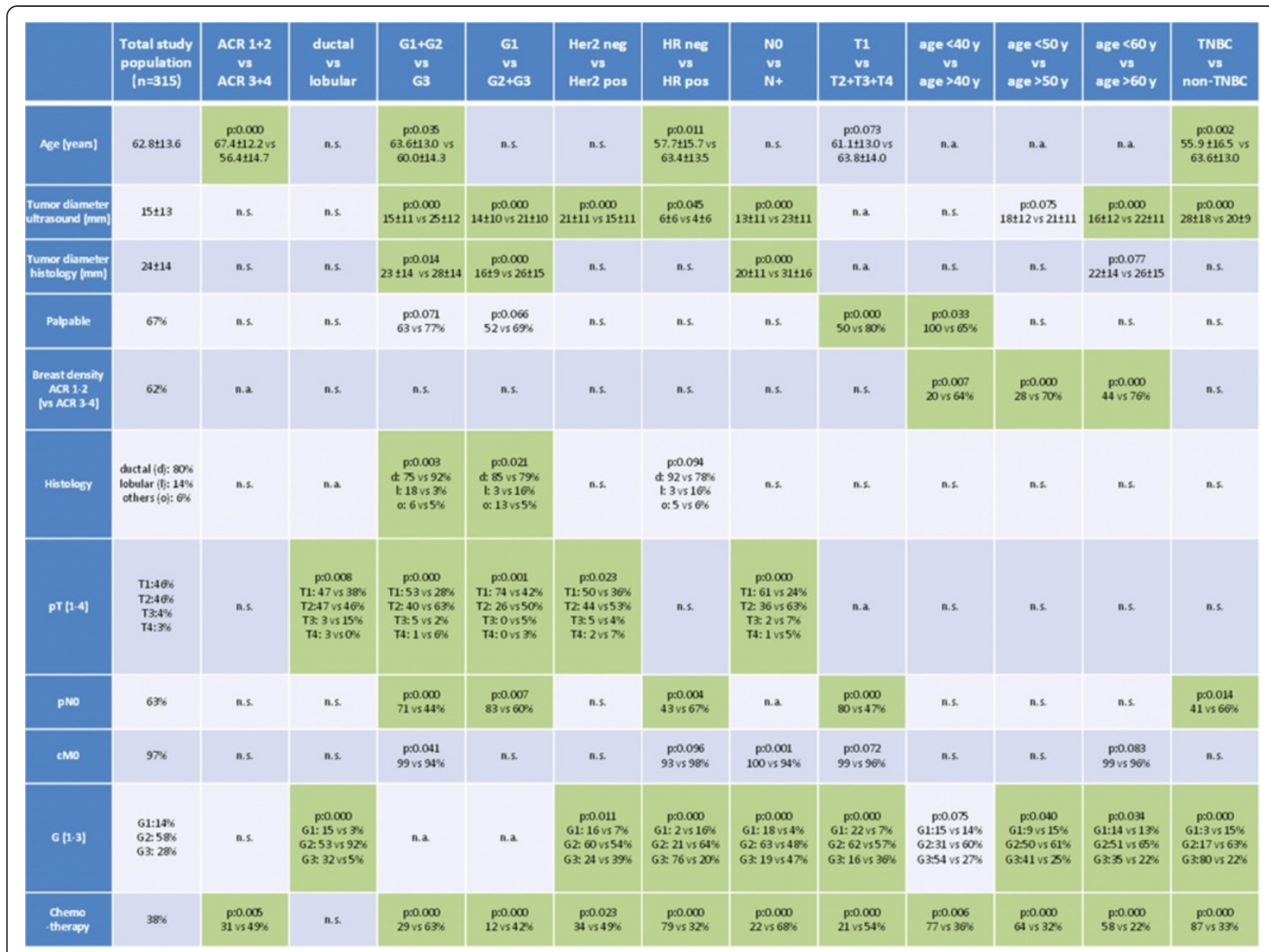

Figure 7 Overview of the results II. Influence of the tumor biology and patient's characteristics on clinical features of the tumor. Significance is indicated in green. P-values greater than $p=0.100$ are indicated as "not significant". (n.a. = not applicable; $n$. s. = not significant; TNBC = triple negative breast cancer; $H R=$ hormone receptors; $d=$ ductal; $I=$ lobular; $\mathrm{o}=$ others).

tumors has moved from the macroscopic over the microscopic to the molecular dimension.

In the first instance, it has to be considered if it is plausible that differences in the molecular attributes of breast cancer can have an impact on the sonomorphology of the tumor. Ultrasound is principally capable of visualizing macroscopic qualities of a mass and thus detecting differences in the gross appearance. However, our results demonstrate that even sub-microscopic features of a tumor may modify its appearance in ultrasound. Understandably, ultrasound cannot directly detect intrinsic parameters of the tumor and it cannot be the aim to predict these parameters by imaging methods. Nevertheless, the typical ultrasound features of malignant breast masses may vary in distinct tumor types. Knowledge about these variations would help the examiner to avoid the false classification of breast lesions. Depending on the chosen groups, we detected a various number of different ultrasound features.

\section{Data from the literature}

The common features of malignant breast tumors are described in specialized books [11]. Furthermore, the American College of Radiology (ACR) has published reference guidelines on the categorization of breast tumors according to their ultrasound characteristics [14]. However, breast cancer cannot be regarded as a single disease and according to histological, immunohistochemical or genetic features, several subtypes can be distinguished [8-10]. Although there has never been a detailed and systematic approach before, we found data in the literature that focuses on certain (sono-) morphologic features of distinct subtypes and that will be discussed in the following sections.

\section{Histological tumor type}

ILC may be occult in both mammography and ultrasound, and breast-MRI may have certain advantages in the detection of this tumor type $[18,19]$. However, the sensitivity of ultrasound seems to be higher than 
mammography (93.9\% versus 79.8\%) [20]. In 2005, Watermann et al. published data on the ultrasound features of ILC cancer [21]. They found that an irregular shape, indistinct margins and posterior acoustic shadowing were described significantly more often in ILC than in other tumor types ( $88 \%$ versus $67 \%, \mathrm{p}<0.001 ; 95 \%$ versus $76 \%$, $\mathrm{p}=0.001 ; 84 \%$ versus $58 \%, \mathrm{p}=0.001$, respectively). These findings partly comply with our own results (85\% versus $71 \%, \mathrm{p}=0.116 ; 97 \%$ versus $94 \%, \mathrm{p}=0.700 ; 59 \%$ versus $45 \%, \mathrm{p}=0.164$ ), as we found corresponding tendencies, but did not reach a level of statistical significance. Nevertheless, we can support the theory that histological differentiation modifies the ultrasonographic appearance of breast cancer. To our interpretation, the posterior acoustic features are of special importance in ILC. We found that posterior acoustic enhancement is observed significantly less often in ILC ( $3 \%$ versus $16 \%, \mathrm{p}=0.023$ ) and either shadowing or mixed features or no features is significantly more frequently observed. The detectability of ILC is often impaired in both mammography and ultrasound as this tumor type has a diffuse and frequently multicentric growth pattern and does not present as a mass. However, a slight architectural distortion with a related posterior acoustic shadowing may be the only hint for this tumor type in ultrasound [22]. The sonographer should be aware of the distinct ultrasound features of ILC in order to avoid false-negative diagnosis. We did not focus on rare histological types of breast malignancies (e.g. mucinous, medullary, tubular, mixed forms, metastases) as these entities only represented a small number of cases in our study. However, we want to emphasize, that these tumors, in particular, tend to exhibit imaging characteristics that are unique and that may be different compared to IDC and ILC. Ultrasound features of these subtypes are described elsewhere [23-27].

\section{HER2 status}

Focusing on the HER2 status, architectural distortions were observed significantly more often in HER2 positive tumors than in HER2 negative tumors (91\% versus $78 \%$ ). Gene amplification and/or protein over-expression of HER2 results in a more aggressive phenotype with increased cell proliferation, motility and tumor invasiveness, accelerated angiogenesis, and reduced apoptosis [28,29]. These biological behaviors imply a rapid infiltration and destruction of the surrounding tissue and, consequently, influence both the macroscopic growth pattern of the tumor and the appearance on ultrasound. The resulting architectural distortions are a reliable predictor for malignancy and occur in the majority of HER2 positive tumors (91\%). Therefore, HER2 positive tumors may be regularly detected and classified as probably malignant by ultrasound. In the literature, we found no conclusive data that could be compared to our results.

\section{Hormone receptor status and triple negativity}

Apparently, the HR status with the associated biological background has a strong impact on the expression of sonographic features. In an earlier analysis of 281 women, Aaltomaa et al. correlated HR status with histological variables and mitotic indices [30]. The authors described a relation to nuclear grade, tumor necrosis, tumor circumscription, inflammatory cell reaction, intraductal growth pattern and tubule formation. The authors concluded that HR negativity implies an increased proliferation rate and a number of malignant histological features in breast lesions. These histological features may explain the variation in the ultrasound characteristics between HR positive and HR negative cancers concerning a lobulated or microlobulated margin, an echogenic halo, the posterior acoustic feature and changes in the Cooper's ligaments. Just recently, Aho et al. published data on 101 breast tumors. The authors concluded, that posterior acoustic shadowing was more often associated with ER positive tumors (90.9\% versus $9.1 \%$ ) and PR positive tumors $(72.7 \%$ versus $27.3 \%)$. This corresponds well with our results ( $47 \%$ versus $20 \%$ ), although the differences are less accentuated in our case series, which can be explained, as we analyzed the global HR status and did not differentiate between ER and PR [31].

\section{Echo pattern}

The most frequently observed echo pattern in breast cancer are hypoechoic tumors (86\%). We found no variables that influence the distribution of echogenicity. Our results comply with reports in the literature that also found no difference in the groups with respect to histological size, grade, axillary metastases, hormone receptor status and lymphovascular invasion [31,32].

\section{Patient's age}

Virtually independent from the cut-off, stratification by age revealed that younger patients were more likely to exhibit round or oval tumors and a lobulated or microlobulated margin. On the other hand, they were less likely to show an echogenic halo, architectural distortions and disruption of the Cooper's ligaments. Consequently, the tumors may lose some of the typical criteria for malignancy in young patients and may be misjudged as benign lesions if the sonographer is not fully aware of this behavior. This phenomenon cannot be explained by the patient's age alone, but must be considered as a coincidental effect that is mainly triggered by the distinct tumor biologies that are common in young patients. Recently, Bullier et al. published data on 97 cases of breast cancer in women under 40 years old [33]. The authors concluded, that young women have more luminal $\mathrm{B} / \mathrm{Her} 2+$ phenotypes and that the appearance of cancers is correlated with their biological profiles. Consequently, 
sonomorphology is mainly driven by the tumor type and not by patient's age. We support this interpretation as our results suggest the same interrelation.

\section{Limitations of our study}

The main limitation of our study is that there was only one observer and image analysis was based on a single, previously acquired still image. Although the observer was blinded, this circumstance may impair some of the results. However, for further studies we would propose to include multiple observers and provide multiple images of each tumor or even video loops. Furthermore, the considerable number of groups and observed variables may boost statistical errors: Following stratification, we performed about 310 comparisons and calculated the statistical significance between the various groups. However, with an error rate of $5 \%$ we could expect no more than 16 positive results by chance. Finally, we found 93 differences that were statistically significant. Therefore, we consider that most of the positive results reflect objective differences between the groups. Nevertheless, it has to be considered that some of the apparent differences between groups may be invalid for statistical reasons.

\section{Conclusions}

Precise evaluation of breast masses before further diagnostic or therapeutic steps has a crucial impact on the quality of the treatment and the outcome in the patient. Lesion assessment by ultrasound is based on the ACR BI-RADS -US classification system that provides a substantial source for the prediction of the malignant or benign aspects of a tumor. Nevertheless, not each breast cancer follows the rules of typical ultrasound criteria for malignancy and variations may occur depending on individual factors, such as patient's characteristics and tumor biology. Usually, round or oval shape is associated with benign lesions, but may also occur in certain types of breast cancer. An echogenic halo is an indicator for malignancy, but it is frequently absent in HR negative tumors. Moreover, posterior acoustic enhancement is associated with benign lesions, but may also occur in high-grade tumors, HR negative tumors and young patients. Finally, architectural distortions are less often observed in small tumors, young patients and Her2 negative tumors.

Therefore, false classification of breast masses may arise with all of the known consequences for the patient. For the advanced sonographer it is essential to be aware of potential variations in the ultrasound morphology of breast tumors. This knowledge would enable the examiner to improve the diagnostic accuracy in the evaluation of breast lesions and finally help to guide the patient in the proper therapeutic direction.

\section{Abbreviations}

ACR: American College of Radiology; D: Ductal; DCIS: Ductal carcinoma in situ; ER: Estrogen receptor; FISH: Fluorescent in situ hybridization; H: Horizontal; HER2: Human epidermal growth factor receptor 2; HR: Hormone receptor; I: Indifferent; IDC: Invasive ductal carcinoma; ILC: Invasive lobular carcinoma; irr.: Irregular; I: Lobular; LN: Lymph node; Microlob: Microlobulated; n.a: not applicable; n.s: not significant; NHG: Nottingham Histology Grade; O: Others; PAF: Posterior acoustic features; PR: Progesterone receptor; TNBC: Triplenegative breast cancer; $\mathrm{V}$ : Vertical.

\section{Competing interests}

The author's declare that they have no competing interests.

\section{Authors' contributions}

SW contributed to the conception and design of the study and FD provided methodological advice. SW and NS performed the data collection and SW evaluated the anonymized ultrasound imaged. NS contributed to the analysis of the data and SW contributed to the interpretation of the results. SW and NS contributed to the writing of the manuscript. PH and FD conducted the final review of the data and the manuscript. SW, NS and FD were employees at the Franziskus Hospital Bielefeld at the time of the study. All authors read and approved the final manuscript.

\section{Acknowledgements}

Publication costs were covered by a grant of the DFG (German Research Foundation) within the project "Open Access Publications" at MHH (Hannover Medical School, Germany). We thank cand. med. Julia Schmidt for arranging the image database.

\section{Author details}

'Department for Obstetrics and Gynecology, Hannover Medical School, Hannover, Germany. ${ }^{2}$ Department for Obstetrics and Gynecology, Helios Hospital Krefeld, Krefeld, Germany. ${ }^{3}$ Department for Obstetrics and Gynecology, Franziskus Hospital Bielefeld, Bielefeld, Germany.

Received: 17 December 2012 Accepted: 15 November 2013

Published: 19 November 2013

\section{References}

1. Bloom HJ, Richardson WW: Histological grading and prognosis in breast cancer; a study of 1409 cases of which 359 have been followed for 15 years. Br J Cancer 1957, 11(3):359-377.

2. Elston CW, Ellis IO: Pathological prognostic factors in breast cancer. I. The value of histological grade in breast cancer: experience from a large study with long-term follow-up. Histopathology 1991, 19(5):403-410.

3. Rakha EA, Reis-Filho JS, Baehner F, Dabbs DJ, Decker T, Eusebi V, Fox SB, Ichihara S, Jacquemier J, Lakhani SR, Palacios J, Richardson AL, Schnitt SJ, Schmitt FC, Tan PH, Tse GM, Badve S, Ellis IO: Breast cancer prognostic classification in the molecular era: the role of histological grade. Breast Cancer Res 2010, 12(4):207.

4. Jensen EV, Jacobson HI: Fate of steroid estrogens in target tissues. In Biological Activities of Steroids in Relation to Cancer. Edited by Pincus G, Vollmer E. New York: NY: Academic; 1960:161-174.

5. Schechter AL, Stern DF, Vaidyanathan L, Decker SJ, Drebin JA, Greene MI, Weinberg RA: The neu oncogene: an erb-B-related gene encoding a 185,000-Mr tumour antigen. Nature 1984, 312(5994):513-516.

6. Menard S, Fortis S, Castiglioni F, Agresti R, Balsari A: HER2 as a prognostic factor in breast cancer. Oncology 2001, 61(Suppl 2):67-72.

7. Hudis CA: Trastuzumab-mechanism of action and use in clinical practice. N Engl J Med 2007, 357(1):39-51.

8. Herschkowitz J, Simin K, Weigman VJ, Mikaelian I, Usary J, Hu Z, Rasmussen $K E$, Jones LP, Assefnia S, Chandrasekharan S, Backlund MG, Yin Y, Khramtsov Al, Bastein R, Quackenbush J, Glazer Rl, Brown PH, Green JE, Kopelovich L, Furth PA, Palazzo JP, Olopade Ol, Bernard PS, Churchill GA, Van Dyke T, Perou CM: Identification of conserved gene expression features between murine mammary carcinoma models and human breast tumors. Genome Biol 2007, 8(5):R76.

9. Perou CM, Sorlie T, Eisen MB, van de Rijn M, Jeffrey SS, Rees CA, Pollack JR, Ross DT, Johnsen H, Akslen LA, Fluge O, Pergamenschikov A, Williams C, Zhu SX, Lonning PE, Borresen-Dale AL, Brown PO, Botstein D: Molecular portraits of human breast tumours. Nature 2000, 406(6797):747-752. 
10. Sorlie T, Perou CM, Tibshirani R, Aas T, Geisler $S$, Johnsen H, Hastie T, Eisen $M B$, van de Rijn M, Jeffrey SS, Thorsen $T$, Quist $H$, Matese JC, Brown PO, Botstein D, Lonning PE, Borresen-Dale AL: Gene expression patterns of breast carcinomas distinguish tumor subclasses with clinical implications. Proc Natl Acad Sci U S A 2001, 98(19):10869-10874.

11. Stavros AT: Breast ultrasound: 1st ed. Philadelphia, PA: Lippincott Williams \& Wilkins; 2004.

12. Sadigh G, Carlos RC, Neal CH, Dwamena BA: Ultrasonographic differentiation of malignant from benign breast lesions: a meta-analytic comparison of elasticity and BIRADS scoring. Breast cancer research and treatment 2012, 133(1):23-35.

13. Berg WA, Zhang Z, Lehrer D, Jong RA, Pisano ED, Barr RG, Bohm-Velez M, Mahoney MC, Evans WP, 3rd Larsen LH, Morton MJ, Mendelson EB, Farria DM, Cormack JB, Marques HS, Adams A, Yeh NM, Gabrielli G: ACRIN 6666 Investigators: Detection of breast cancer with addition of annual screening ultrasound or a single screening MRI to mammography in women with elevated breast cancer risk. JAMA 2012, 307(13):1394-1404.

14. Mendelson EB, Baum JK, Berg WA, Merritt CR, Rubin E: BI-RADS: Ultrasound. In Breast Imaging Reporting and Data System: ACR BI-RADS - Breast Imaging Atlas. Edited by D'Orsi CJ, Mendelson EB, Ikeda DM. Reston, VA: American College of Radiology; 2002

15. Wojcinski S, Soliman AA, Schmidt J, Makowski L, Degenhardt F, Hillemanns $P$ : Sonographic features of triple-negative and non-triple-negative breast cancer. J Ultrasound Med 2012, 31(10):1531-1541.

16. DEGUM (Deutsche Gesellschaft für Ultraschall in der Medizin, German Association for Ultrasound in Medicine) - Mehrstufenkonzept Mammasonographie. [http://www.degum.de/Mehrstufenkonzept_Mammasonogra.634.0.html]

17. Madjar $\mathrm{H}$, Ohlinger $\mathrm{R}$, Mundinger A, Watermann D, Frenz JP, Bader W, Schulz-Wendtland R, Degenhardt F: BI-RADS-analogue DEGUM criteria for findings in breast ultrasound-consensus of the DEGUM Committee on Breast Ultrasound. Ultraschall Med 2006, 27(4):374-379

18. Cocquyt $V$, Van Belle S: Lobular carcinoma in situ and invasive lobular cancer of the breast. Curr Opin Obstet Gynecol 2005, 17(1):55-60.

19. Mann RM: The effectiveness of MR imaging in the assessment of invasive lobular carcinoma of the breast. Magn Reson Imaging Clin N Am 2010, 18(2):259-276. ix.

20. Tan SM, Behranwala KA, Trott PA, Nasiri NA, Moskovic E, Brown G, King DM, Sacks NP, Gui GP: A retrospective study comparing the individual modalities of triple assessment in the pre-operative diagnosis of invasive lobular breast carcinoma. Eur J Surg Oncol 2002, 28(3):203-208.

21. Watermann DO, Tempfer C, Hefler LA, Parat C, Stickeler E: Ultrasound morphology of invasive lobular breast cancer is different compared with other types of breast cancer. Ultrasound Med Biol 2005, 31(2):167-174.

22. Kim SH, Cha ES, Park CS, Kang BJ, Whang IY, Lee AW, Song BJ, Park J: Imaging features of invasive lobular carcinoma: comparison with invasive ductal carcinoma. Jpn J Radiol 2011, 29(7):475-482.

23. Cheung YC, Chen SC, Lee KF, Wan YL, Ng SH: Sonographic and pathologic findings in typical and atypical medullary carcinomas of the breast. J Clin Ultrasound 2000, 28(7):325-331.

24. Mitnick JS, Gianutsos R, Pollack AH, Susman M, Baskin BL, Ko WD, Pressman PI, Feiner HD, Roses DF: Tubular carcinoma of the breast: sensitivity of diagnostic techniques and correlation with histopathology. AJR Am J Roentgenol 1999, 172(2):319-323.

25. Memis A, Ozdemir N, Parildar M, Ustun EE, Erhan Y: Mucinous (colloid) breast cancer: mammographic and US features with histologic correlation. Eur J Radiol 2000, 35(1):39-43.

26. Yang WT, Muttarak M, Ho LW: Nonmammary malignancies of the breast: ultrasound, CT, and MRI. Semin Ultrasound CT MR 2000, 21(5):375-394.

27. Wojcinski S, Farrokh A, Weh HJ, Williams J, Wiskirchen J: Degenhardt F: [Clinical Image: Breast metastasis from rectal carcinoma]. Senologie Zeitschrift für Mammadiagnostik und -therapie 2012, 9:63-65.

28. Ross JS, Slodkowska EA, Symmans WF, Pusztai L, Ravdin PM, Hortobagyi GN: The HER-2 receptor and breast cancer: ten years of targeted anti-HER-2 therapy and personalized medicine. Oncologist 2009, 14(4):320-368.

29. Moasser MM: The oncogene HER2: its signaling and transforming functions and its role in human cancer pathogenesis. Oncogene 2007, 26(45):6469-6487.

30. Aaltomaa S, Lipponen P, Eskelinen M, Kosma VM, Marin S, Alhava E, Syrjanen $\mathrm{K}$ : Hormone receptors as prognostic factors in female breast cancer. Ann Med 1991, 23(6):643-648.
31. Aho M, Irshad A, Ackerman SJ, Lewis M, Leddy R, Pope TL, Campbell AS, Cluver A, Wolf BJ, Cunningham JE: Correlation of sonographic features of invasive ductal mammary carcinoma with age, tumor grade, and hormone-receptor status. J Clin Ultrasound 2013, 41(1):10-17.

32. Soon PS, Vallentine J, Palmer A, Magarey CJ, Schwartz P, Morris DL: Echogenicity of breast cancer: is it of prognostic value? Breast 2004, 13(3):194-199

33. Bullier B, Macgrogan G, Bonnefoi $H$, Hurtevent-Labrot $G$, Lhomme E, Brouste $\checkmark$, Boisserie-Lacroix M: Imaging features of sporadic breast cancer in women under 40 years old: 97 cases. Eur Radiol 2013, 23(12):3237-3245.

doi:10.1186/1472-6874-13-47

Cite this article as: Wojcinski et al:: The biology of malignant breast tumors has an impact on the presentation in ultrasound: an analysis of 315 cases. BMC Women's Health 2013 13:47.

\section{Submit your next manuscript to BioMed Central and take full advantage of:}

- Convenient online submission

- Thorough peer review

- No space constraints or color figure charges

- Immediate publication on acceptance

- Inclusion in PubMed, CAS, Scopus and Google Scholar

- Research which is freely available for redistribution

Submit your manuscript at www.biomedcentral.com/submit
C) Biomed Central 